\title{
VITAMIN D STATUS AND HEALTH CORRELATES AMONG APPARENTLY HEALTHY PARTICIPANTS IN AN URBAN, SUNNY REGION
}

\author{
Natalia Vallianou' ${ }^{1}$, Vassiliki Bountziouka ${ }^{2}$, Thanasis Akalestos ${ }^{3}$, Angelos Evangelopoulos ${ }^{3}$, Evangelos \\ Vogiatzakis ${ }^{1}$, Maria Bonou', John Barbetseas ${ }^{1}$, Peter C. Avgerinos ${ }^{1}$, Demosthenes B. Panagiotakos ${ }^{2}$ \\ ${ }^{1}$ General Hospital of Athens "Polykliniki", Athens, Greece \\ ${ }^{2}$ Department of Science of Dietetics-Nutrition, Harokopio University of Athens, Athens, Greece \\ ${ }^{3}$ Roche Diagnostics (Hellas) S.A, Athens, Greece
}

\section{SUMMARY}

Aim: To assess vitamin D status and health correlates in a sample of apparently healthy Caucasian participants residing in an urban area, Athens, with latitude $37058^{\prime} 0^{\prime \prime} \mathrm{N}$ and longitude $23043^{\prime} \mathrm{O}^{\prime \prime} \mathrm{E}$, after taking into consideration a broad range of purported biological, behavioural and environmental factors.

Method: Men and women 35+ years from a selected population $(n=490)$ were studied. Participants completed a detailed questionnaire regarding socio-demographic, lifestyle, clinical and dietary characteristics. Biomarkers were measured after $12 \mathrm{~h}$ fasting. Linear and multinomial regression models were used to evaluate the association between $25(\mathrm{OH}) \mathrm{D}$ and determinants of vitamin $\mathrm{D}$ status.

Results: Results revealed that one hour increase of sunlight exposure decreased the odds of having D deficiency (i.e., $<20 \mathrm{ng} / \mathrm{mL}$ ) by $70 \%$ (OR=0.30, 95\% Cl: 0.20-0.45), adjusted for age, sex, family status, physical activity, smoking habits, BMl, triglycerides, parathyroid hormone, uric acid, haptoglobin, folate acid and haemoglobin, as compared to sufficient levels (i.e., >30 ng/mL). Regarding biomarkers, parathyroid hormone and haptoglobin were found to be related with the odds of having vitamin $\mathrm{D}$ deficiency $(\mathrm{OR}=1.11,95 \% \mathrm{Cl}: 1.05-1.16 ; \mathrm{OR}=1.02,95 \% \mathrm{Cl}$ : $1.00-1.03$, respectively) as compared to the sufficient levels.

Conclusions: Sufficient serum vitamin D levels were observed among participants with characteristics associated with reduced cardiovascular risk, such as normal BMI, increased physical activity, decreased parathyroid hormone and decreased inflammatory markers. Even a slight increase in sunlight exposure could have beneficial effects on serum vitamin D concentrations and eventually on haemoglobin and inflammatory markers levels, thus providing a simple and inexpensive lifestyle intervention that promotes public health.

Key words: vitamin D, sunshine, inflammation, cardiovascular risk, haemoglobin

Address for correspondence: N. Vallianou, 5 Pyramidon, 19005 Athens, Greece. E-mail: natalia.vallianou@hotmail.com

\section{INTRODUCTION}

Vitamin D has two forms, vitamin D2 and vitamin D3, also called ergocalciferol and cholecalciferol, respectively. Vitamin D3 is produced in the skin in response to ultraviolet $\mathrm{B}$ radiation from sunlight or can be obtained from the diet (i.e., animal sources such as deep sea fatty fish, egg yolks, or liver) or from supplements. Both forms of vitamin D are converted to 25-hydroxyvitamin $\mathrm{D}[25(\mathrm{OH}) \mathrm{D}]$ in the liver, and the serum levels of $25(\mathrm{OH}) \mathrm{D}$ are measured to determine vitamin D status. Serum 25(OH)D is considered the best functional indicator of vitamin D status reflecting the sum of cutaneous synthesis and oral intake (1).

There is a critical requirement of vitamin $\mathrm{D}$ for bone and mineral homeostasis, and in particular in preventing rickets and osteomalacia. Inadequate vitamin D blood level has been implicated in increased risk for osteoporosis, cardiovascular disease, diabetes, cancer and autoimmune diseases such as multiple sclerosis $(2-5)$. However, the blood levels of $25(\mathrm{OH}) \mathrm{D}$ that define vitamin D deficiency remain somewhat controversial. Currently, most agree that vitamin D concentration below $20 \mathrm{ng} / \mathrm{ml}$ indicates vitamin D deficiency, whereas a concentration of $21-29 \mathrm{ng} / \mathrm{ml}$ is considered insufficient, and a $25(\mathrm{OH}) \mathrm{D}$ level of $30-100 \mathrm{ng} / \mathrm{ml}$ defines vitamin D sufficiency (6).

Vitamin D deficiency is currently considered an important public health problem. It has been estimated that 1 billion people worldwide suffer from vitamin D deficiency (7). Children and adolescents are also potentially at high risk for vitamin D deficiency, especially at high latitudes at the end of the winter. Unfortunately, very few foods naturally contain vitamin $\mathrm{D}$, and even fewer are fortified. Besides, above $37^{\circ}$ latitude during the winter months very little if any vitamin D3 is produced in the skin. These are some of the main reasons why vitamin D deficiency has become epidemic for all age groups in the United States and Europe (8). In fact, no one is immune from vitamin D deficiency.

Up to date, data regarding Caucasian populations are limited and there is a concern regarding the potential role of vitamin D deficiency in the Mediterranean region and especially in the Greek population. Additionally, to the best of our knowledge, a broad range of purported biological (age, sex body mass index (BMI), behavioural (vitamin D from diet, supplements and medications, 
activity), and environmental factors (season, sun exposure), which may be independently associated with vitamin D status, has not been examined previously. Thus, this study aimed to assess vitamin D status based on the distribution and seasonal variation of $25(\mathrm{OH}) \mathrm{D}$ in a cohort of Greek adults $\geq 35$ years old and examine the multivariable relationship between vitamin D status and anthropometric, lifestyle, and clinical characteristics.

\section{MATERIALS AND METHODS}

\section{Participants}

Between April 2009 and January 2010, a convenience sample of 490 adults out of the total number of people who had visited the "Polykliniki" General Hospital for an annual health check-ups, agreed to participate in the study (85\%). Individuals with history of cancer or recent infection were not included in the study. The retrieved data were confidential and the study followed the ethical considerations outlined by the World Medical Association (9). Moreover, the Institutional Review Board approved the design, procedures and aims of the study (GA 23/14.05.2009). All participants were informed about procedures of the study and agreed to participate providing written informed consent.

\section{Anthropometric and Lifestyle Characteristics}

All participants were Caucasians. Age (years), gender (males vs. females) and marital status [i.e., single (single, divorced, widowed) vs. married] were assessed using a self-reported questionnaire. With respect to lifestyle characteristics, participants were asked to fill in a 10-grade scale range regarding their physical activity status (grade of scale used: 1-10, where 1 denotes sedentary lifestyle and 10 daily hard activities of at least 30 minutes). Participants with score $\leq 6$ were classified as low/moderately active, while those with score $>6$ were considered as highly active. Participants were also asked to answer how often they consume alcoholic drinks (i.e., beer, wine and other spirits) using a valid semi-quantitative food frequency questionnaire (FFQ) (10). Alcohol consumption was then assessed as the frequency of drinking per day and participants were categorized as never ( 0 times/ day), rare (i.e., $0.01-1$ times/day), and often (i.e., $\geq 1$ times/day). In addition, the MedDietScore (range 0-55) was also calculated to evaluate adherence to Mediterranean diet. Higher values of this score indicate greater adherence to the specific pattern (11). Current smoking was defined as those who smoke at least 1 cigarette a day for the past year. The average sunlight (in hours) according to BBC weather for Athens was used to estimate the mean sunlight exposure of participants during 2009 (http://news. bbc.co.uk/weather/hi/about/, assessed September 2010).

Hypertension was defined as a systolic blood pressure $\geq 140$ $\mathrm{mmHg}$ and/or a diastolic blood pressure $\geq 90 \mathrm{mmHg}$ or the use of anti-hypertensive drugs. Coronary heart disease, heart failure, cerebrovascular disease, and peripheral arterial disease were assessed by self-report and medication use. Diabetes was assessed by self-report, medication use or a positive diagnosis by fasting blood glucose level ( $\geq 126 \mathrm{mg} / \mathrm{dL}$ ). Hypercholesterolemia was defined as a serum cholesterol $\geq 200 \mathrm{mg} / \mathrm{dL}$ or by the use of cholesterol-lowering drugs. Waist and height were measured to the nearest $0.5 \mathrm{~cm}$, without shoes, and weight was measured with a lever balance, to the nearest $100 \mathrm{~g}$, without shoes, in light undergarments. Body mass index (BMI) was calculated as weight in kilograms divided by the square of height in meters. Blood pressure was measured twice by the same physician using a standard mercury sphygmomanometer on the right arm of the seated subject.

Venipuncture was performed in each participant, early in the morning (between 7 am to $11 \mathrm{am}$ ), after a 12 hour fasting period.

\section{Laboratory Analyses}

Serum 25(OH)D, intact parathyroid hormone (iPTH), vitamin B12, and folate acid measurements were performed on a Roche/ Modular Analytics analyzer, which employs electrochemilluminescense immunoassay technology (ECLIA). The intra- and inter-assay coefficients of variation (CVs) of the vitamin D3 $(25-\mathrm{OH})$ assay were less than $10 \%$ and the analytical sensitivity was $4 \mathrm{ng} / \mathrm{mL}$. The intra- and inter-assay coefficients of variation (CVs) of the intact PTH assay were less than $7 \%$ and the analytical sensitivity was $1.2 \mathrm{pg} / \mathrm{mL}$. The intra- and inter-assay coefficients of variation (CVs) of the Vitamin B12 assay were less than 8\% and the analytical sensitivity was $30 \mathrm{pg}$. The intra- and inter-assay coefficients of variation (CVs) of the folate assay were less than $10 \%$ and the analytical sensitivity was $0.64 \mathrm{ng} / \mathrm{mL}$. Glucose, total cholesterol, HDL cholesterol, triglycerides and serum albumin were determined by enzymatic colorimetric tests (GOD-PAP, CHOD-PAP Abell-Kendal, HDL cholesterol without pretreatment, GPO-PAP and BCG respectively). Serum creatinine was determined via a kinetic colorimetric assay based on the reaction of creatinine with picric acid in alkaline solution. Estimated GFR (eGFR) was calculated using the creatinine-based four-variable Modification of Diet in Renal Disease (MDRD) equation. Cystatin $\mathrm{C}$, hsCRP and ferritin, haptoglobin were determined via immunoturbidimetric assays. All measurements were performed on a Roche/Modular Analytics analyzer. Reagents, calibrators, controls and consumables were purchased from the same supplier (Roche Diagnostics GmbH, Sandhofer Strasse 116, D-68305 Mannheim, Germany). Hematology parameters were determined in an automated hematology analyzer (Advia 2120, Siemens).

Participants were classified in three categories according to their 25(OH)D serum levels as follows: deficient $<20 \mathrm{ng} / \mathrm{mL}$, insufficient $20-30 \mathrm{ng} / \mathrm{mL}$ and sufficient $>30 \mathrm{ng} / \mathrm{mL}$ (6).

\section{Statistical Analysis}

Results are presented as mean values \pm SD for the normally distributed continuous variables (i.e., age, sunlight exposure, MedDietScore, total cholesterol, HDL cholesterol, LDL cholesterol, calcium, glomerular filtration rate, haptoglobin, haemoglobin, platelets), as median (1st-3rd quartile) for the skewed ones (i.e., triglycerides, parathyroid hormone, urea, uric acid, C-reactive protein, cystatin C, vitamin B12, folate acid, iron, ferritin, white blood cells) and as frequencies [N (\%)] for the categorical variables (i.e., gender, family status, physical activity, smoking, obesity status, drinking). Normality was tested using graphical methods (i.e., P-P plots and histograms). Differences between three groups of vitamin D status with respect to participants' socio-demographic, anthropometric, lifestyle, and biomarkers' characteristics were evaluated using the one-way ANOVA F-test for the normally distributed variables, the Kruskal-Wallis H-test for the skewed ones and the chi-square test for the categorical ones. 
The association of blocks of biomarkers (i.e., lipid profile, calcium metabolism, renal function, inflammatory markers, anaemia markers, blood disorders biomarkers) with the serum vitamin D levels were tested after taking into consideration a series of socio-demographic (i.e., age, gender, marital status) and lifestyle factors (i.e., sunlight exposure, physical activity status, smoking, drinking, prevalence of obesity) using additive regression models. The results are presented as regression coefficients (b) and their standard errors (SE). Biomarkers from each block that were found to significantly influence the blood levels of vitamin D according to regression models, were further entered into multinomial logistic regression models to evaluate the odds of having deficient/insufficient vitamin D levels $(<20 \mathrm{ng} / \mathrm{mL}$ or $20-30 \mathrm{ng} / \mathrm{mL}$ ) as compared to sufficient levels range (>30 ng/ $\mathrm{mL})$. Multinomial regression models were further adjusted for age, gender, sunlight exposure, family status, physical activity level, overweight/obese status and smoking.

\section{RESULTS}

Participants' descriptive characteristics regarding serum vitamin D levels are presented in Table 1. Compared to those with lower vitamin D levels, participants with sufficient vitamin D values were younger $(p<0.001)$ with higher mean hours of sunlight exposure $(\mathrm{p}<0.001)$, and higher proportion of higher activity $(p=0.01)$, smokers $(p=0.005)$, normal weighted $\left(B M I<25 \mathrm{~kg} / \mathrm{m}^{2}\right)$ and rare and frequent drinkers $(\mathrm{p}=0.02)$. In Table 2 , distribution of participant's characteristics as regards various biomarkers is presented. Participants with higher vitamin D values had lower concentrations of triglycerides $(p=0.006)$, calcium $(p=0.004)$, urea $(p=0.03), C$-reactive protein $(p=0.002)$, haptoglobin $(p=0.02)$ and cystatin $C(p<0.001)$, and higher values of glomerular filtration rate $(p<0.001)$ and haemoglobin $(p<0.001)$. Associations of vitamin D deficiency with glucose, blood pressure and metabolic syndrome failed to be revealed (data not shown in Tables).

To further assess the effect of various factors on serum Vitamin D levels additive linear models were performed and results are presented in Table 3. Male participants had on average higher values of Vitamin D blood levels by $2.2 \mathrm{ng} / \mathrm{mL}$ ( $\mathrm{SE}=0.70, \mathrm{p}=0.002$ ) as compared to females, following adjustment for age and sunlight exposure. In contrast, Vitamin D concentration decreased by $0.17 \mathrm{ng} / \mathrm{mL}$ with each year of age ( $\mathrm{b} \pm \mathrm{SE}:-0.17 \pm 0.02, \mathrm{p}<0.001)$, gender and sunlight exposure adjusted. This trend did not seem to alter even when additional socio-demographic (i.e., family status) and lifestyle (i.e., physical activity, smoking habits, drinking habits, BMI) characteristics were also included in the model. The analysis was additionally performed taking into account blocks of relevant biomarkers. Age and gender effect on serum vitamin D levels remained significant when the lipids block (i.e., HDL cholesterol, LDL cholesterol, triglycerides) and the anaemia biomarkers (i.e., vitamin B12, iron, folate acid, ferritin) were also taken into account. Sunlight exposure remained a significant factor in cases of all biomarkers blocks tested (Table 3). Total cholesterol was dropped due to collinearity in Table 3.

Table 1. Participants socio-demographic and lifestyle characteristics according to Vitamin D serum level categories

\begin{tabular}{|c|c|c|c|c|}
\hline & \multicolumn{3}{|c|}{ Vitamin D categories } & \multirow[b]{2}{*}{$P^{*}$} \\
\hline & $\begin{array}{c}<20 \mathrm{ng} / \mathrm{mL} \\
(\mathrm{N}=135)\end{array}$ & $\begin{array}{c}20-30 \mathrm{ng} / \mathrm{mL} \\
(\mathrm{N}=217)\end{array}$ & $\begin{array}{c}>30 \mathrm{ng} / \mathrm{mL} \\
(\mathrm{N}=120)\end{array}$ & \\
\hline Male gender, $\mathrm{N}(\%)$ & $47(35)$ & $84(39)$ & $55(46)$ & 0.19 \\
\hline Age (years) & $51 \pm 17$ & $46 \pm 15$ & $40 \pm 14$ & $<0.001$ \\
\hline \multicolumn{5}{|l|}{ Family status, N (\%) } \\
\hline Single & $37(27)$ & $72(33)$ & $52(43)$ & \multirow{4}{*}{0.17} \\
\hline Married & $85(63)$ & $126(58)$ & $58(48)$ & \\
\hline Divorced & $9(6.7)$ & $14(6.5)$ & $5(4.2)$ & \\
\hline Widowed & $4(3.0)$ & $5(2.3)$ & $5(4.2)$ & \\
\hline Sunlight exposure (hours) & $8.0 \pm 2.6$ & $9.3 \pm 2.6$ & $11 \pm 2.1$ & $<0.001$ \\
\hline \multicolumn{5}{|l|}{ Physical activity, N (\%) } \\
\hline Sedentary/low & $33(24)$ & $47(22)$ & $12(10)$ & \multirow{3}{*}{0.01} \\
\hline Moderate & $81(60)$ & $126(58)$ & $74(62)$ & \\
\hline High & $21(16)$ & $44(20)$ & $34(28)$ & \\
\hline Smoking (yes vs. no), N (\%) & $28(21)$ & $77(35)$ & $45(38)$ & 0.005 \\
\hline Overweight/ Obesity (yes vs. no), N (\%) & $87(65)$ & $127(59)$ & $59(50)$ & 0.04 \\
\hline MedDietScore, 0-55 & $29.9 \pm 4.56$ & $29.7 \pm 4.21$ & $29.5 \pm 3.66$ & 0.77 \\
\hline \multicolumn{5}{|l|}{ Drinking, N (\%) } \\
\hline Never & $55(41)$ & $86(40)$ & $30(25)$ & \multirow{3}{*}{0.02} \\
\hline Rare (<1times/day) & $53(39)$ & $80(37)$ & $48(40)$ & \\
\hline Often ( $\geq 1$ times/day) & $27(20)$ & $51(24)$ & $42(35)$ & \\
\hline
\end{tabular}

Results presented as mean \pm SD or absolute frequencies (and percentage)

${ }^{*}$ P-values derived through the one-way ANOVA F-test for the continuous variables (i.e., age and sunlight exposure), and the Chi-square test for the categorical ones (i.e., sex, family status, physical activity, smoking, prevalence of overweight and obesity and drinking). 
Table 2. Distribution of participants' biomarkers characteristics according to Vitamin D blood level categories

\begin{tabular}{|c|c|c|c|c|}
\hline & \multicolumn{3}{|c|}{ Vitamin D categories } & \multirow{2}{*}{$P^{* *}$} \\
\hline & $<20 \mathrm{ng} / \mathrm{mL}$ & $20-30 \mathrm{ng} / \mathrm{mL}$ & $>30 \mathrm{ng} / \mathrm{mL}$ & \\
\hline \multicolumn{5}{|l|}{ Biomarkers* } \\
\hline Total cholesterol (mg/dL) & $201 \pm 38$ & $201 \pm 39$ & $197 \pm 44$ & 0.55 \\
\hline HDL-cholesterol (mg/dL) & $51 \pm 15$ & $50 \pm 14$ & $48 \pm 13$ & 0.32 \\
\hline LDL-cholesterol (mg/dL) & $127 \pm 33$ & $128 \pm 34$ & $128 \pm 40$ & 0.90 \\
\hline Triglycerides (mg/dL) & $105(73-146)$ & $96(69-133)$ & $80(56-126)$ & 0.006 \\
\hline Calcium (mg/dL) & $10 \pm 0.47$ & $9.5 \pm 0.43$ & $9.3 \pm 0.45$ & 0.004 \\
\hline Parathyroid hormone (pg/mL) & $44(35-63)$ & $43(34-58)$ & $41(31-49)$ & 0.10 \\
\hline Estimated glomerular filtration rate $(\mathrm{mL} / \mathrm{min})$ & $99 \pm 22$ & $106 \pm 19$ & $110 \pm 15$ & $<0.001$ \\
\hline Urea (mg/dL) & $36(30-44)$ & $34(29-41)$ & $33(28-39)$ & 0.03 \\
\hline Uric acid (mg/dL) & $4.8(3.8-6.0)$ & $5.0(4.0-6.0)$ & $4.7(3.8-6.0)$ & 0.61 \\
\hline C-reactive protein (mg/dL) & $0.10(0.00-0.30)$ & $0.10(0.10-0.30)$ & $0.10(0.00-0.20)$ & 0.002 \\
\hline Haptoglobin (mg/dL) & $138 \pm 66$ & $126 \pm 49$ & $113 \pm 49$ & 0.02 \\
\hline Cystatin C (mg/L) & $0.88(0.8-1.0)$ & $0.83(0.74-0.92)$ & $0.78(0.71-0.83)$ & $<0.001$ \\
\hline Vitamin B12 (pg/mL) & $403(317-502)$ & $403(332-533)$ & $393(288-457)$ & 0.28 \\
\hline Folate acid (ng/mL) & $8.2(6.2-10)$ & $7.6(5.9-11)$ & $7.5(5.9-10)$ & 0.95 \\
\hline Iron (ig/dL) & $86(66-110)$ & $87(68-117)$ & $89(70-119)$ & 0.48 \\
\hline Ferritin (ng/dL) & $66(28-110)$ & $61(33-118)$ & $69(29-131)$ & 0.85 \\
\hline Haemoglobin (g/dL) & $13 \pm 1.3$ & $14 \pm 1.4$ & $14 \pm 1.3$ & $<0.001$ \\
\hline Platelets (10^9/L) & $228 \pm 59$ & $234 \pm 55$ & $233 \pm 44$ & 0.53 \\
\hline White blood cells (10^9/L) & $6.8(5.7-8.1)$ & $7.1(6.0-8.4)$ & $6.9(6.0-8.1)$ & 0.27 \\
\hline
\end{tabular}

${ }^{*}$ Results are presented as mean \pm SD for the normally distributed variables (i.e., total cholesterol, HDL-cholesterol, LDL-cholesterol, Calcium, Glomerular Filtration Rate, Haptoglobin, Haemoglobin and Platelets), and as median (1st-3rd quartile) for the skewed ones (i.e., Triglycerides, Parathyroid hormone, Urea, Uric acid, C-reactive protein, Cystatin C, Vitamin B12, Folate acid, Iron, Ferritin and White blood cells.)

${ }^{* *} \mathrm{P}$-values derived through the one-way ANOVA F-test for the normally distributed variables and the Kruskal-Wallis $\mathrm{H}$-test for the skewed ones.

Biomarkers that were significant predictors of serum vitamin D levels were further included to multinomial regression model to further identify factors related with deficient/insufficient vitamin D levels as compared to sufficient levels (i.e., $>30 \mathrm{ng} / \mathrm{mL}$ ). Results revealed that one hour increase of sunlight exposure decreased the odds of vitamin D deficiency (i.e., $<20 \mathrm{ng} / \mathrm{dL}$ ) by $70 \%$ (OR $=0.30$, 95\% CI: 0.20-0.45), adjusted for age, sex, family status, physical activity, smoking habits, BMI, triglycerides, parathyroid hormone, uric acid, haptoglobin, folate acid and haemoglobin, as compared to the sufficient levels (i.e., $>30 \mathrm{ng}$ / $\mathrm{mL}$ ). Regarding biomarkers, participants with higher levels of parathyroid hormone and haptoglobin were found to have higher odds of falling into deficient versus sufficient vitamin D category $(\mathrm{OR}=1.11,95 \% \mathrm{CI}: 1.05-1.16$; OR $=1.02,95 \% \mathrm{CI}: 1.00-1.03$, respectively). In addition, increased sunlight exposure was also found to be related with $41 \%$ reduction in odds of vitamin D insufficiency (i.e., $20-30 \mathrm{ng} / \mathrm{mL})$ by $51 \%(\mathrm{OR}=0.59,95 \% \mathrm{CI}$ : 0.45-0.77), adjusted for age, sex, family status, physical activity, smoking habits, BMI, triglycerides, parathyroid hormone, uric acid, haptoglobin, folate acid and haemoglobin as compared to the sufficient levels. Parathyroid hormone was the only biomarker that was found to be related with the odds of deficient/insufficient vitamin D levels. In particular, the odds of vitamin D deficiency was increased by $4 \%$ per $1 \mathrm{pg} / \mathrm{mL}$ of parathyroid hormone as compared to those having sufficient values of vitamin $\mathrm{D}$, adjusted for age, sex, sunlight exposure, family status, physical activity, smoking habits, BMI, triglycerides, uric acid, haptoglobin, folate acid and haemoglobin (Table 4).

\section{DISCUSSION}

In this study, sufficient vitamin D concentrations were observed in younger, normal weighted participants, with higher physical activity and increased sunlight exposure contrary to subjects with deficient or insufficient vitamin D levels. It is widely known that the elderly are at risk of vitamin D deficiency because of decreased sunlight exposure, decreased dietary vitamin D intake, reduced capacity to produce cholecalciferol and reduced physical activity $(12,13)$. This trend did not change even after adjustment for various socio-demographic (age, gender, family status) and lifestyle factors (sunlight exposure, physical activity, smoking, alcohol intake, BMI) leading to the conclusion that aging is an independent factor associated with lower blood levels of vitamin D. In fact, even just one year increase in age was associated with a statistically significant decrease in vitamin D concentrations. Sunlight exposure was associated with sufficient levels of vitamin D even after adjustment for the above-mentioned socio-demographic and lifestyle factors as well as for biomarkers that were found to be significant predictors of serum vitamin D levels. 


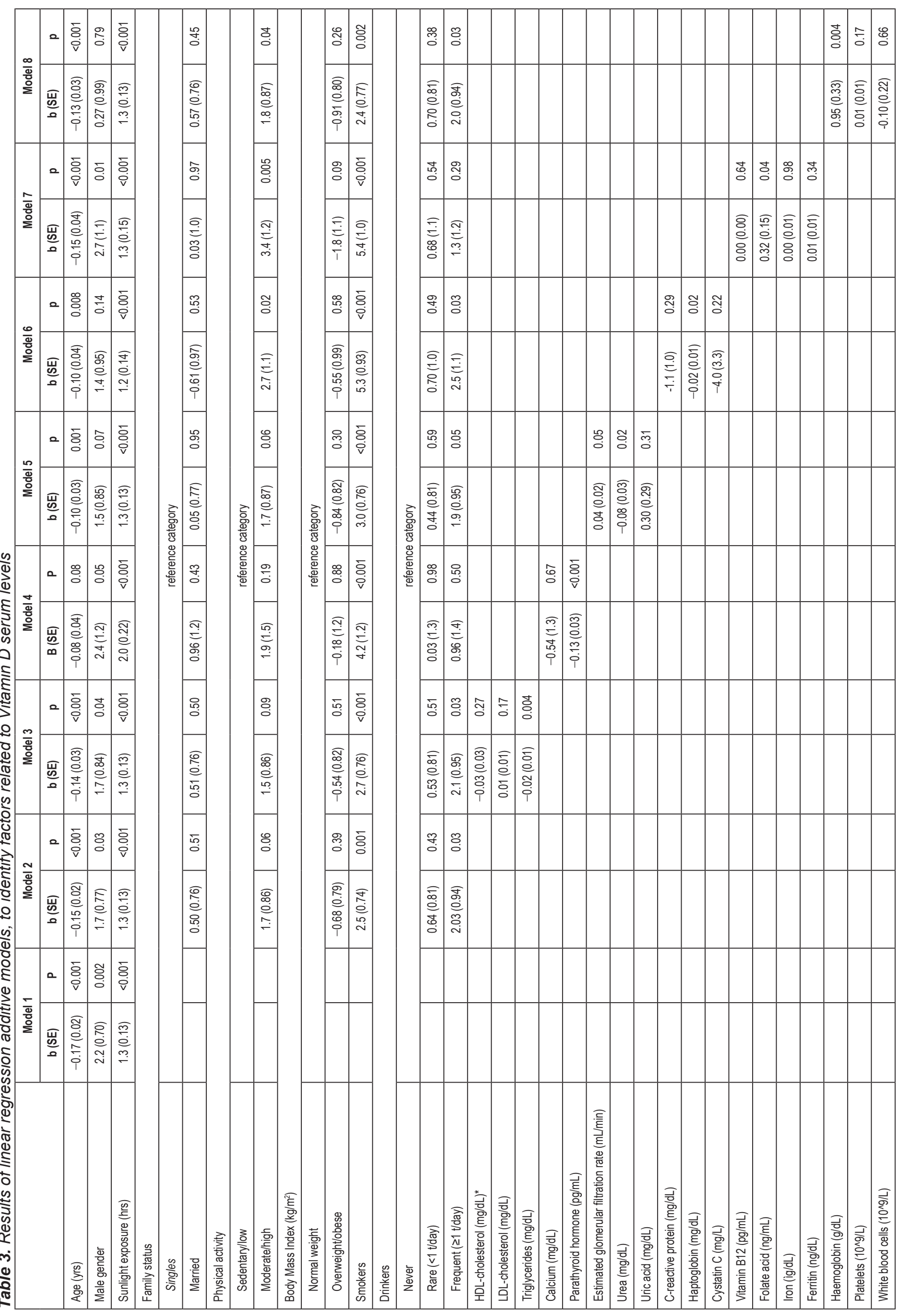


Table 4. Results of multinomial regression to evaluate the effect of socio-demographic and clinical characteristics on Vitamin $D$ serum levels

\begin{tabular}{|c|c|c|c|c|c|c|}
\hline & \multicolumn{6}{|c|}{ Vitamin D categories* } \\
\hline & \multicolumn{3}{|c|}{ Deficient vs. Sufficient } & \multicolumn{3}{|c|}{ Insufficient vs. Sufficient } \\
\hline & OR & $95 \% \mathrm{Cl}$ & $\mathbf{P}$ & OR & $95 \% \mathrm{Cl}$ & $\mathbf{P}$ \\
\hline Age (years) & 1.01 & $(0.95-1.07)$ & 0.74 & 1.02 & $(0.98-1.07)$ & 0.25 \\
\hline Male gender & 1.16 & $(0.15-8.66)$ & 0.89 & 1.19 & $(0.28-4.99)$ & 0.81 \\
\hline Sunlight exposure (hours) & 0.30 & $(0.20-0.45)$ & $<0.001$ & 0.59 & $(0.45-0.77)$ & $<0.001$ \\
\hline \multicolumn{7}{|l|}{ Family status } \\
\hline Singles** & 1.00 & & & 1.00 & & \\
\hline Married & 1.12 & $(0.23-5.4)$ & 0.89 & 0.96 & $(0.34-2.68)$ & 0.94 \\
\hline Physical activity (1-10) & 0.18 & $(0.02-1.41)$ & 0.10 & 0.26 & $(0.06-1.25)$ & 0.09 \\
\hline \multicolumn{7}{|l|}{ Body Mass Index } \\
\hline Normal weight & 1.00 & & & 1.00 & & \\
\hline Overweight/obese & 2.10 & $(0.41-11)$ & 0.37 & 1.22 & $(0.45-3.36)$ & 0.70 \\
\hline Smokers & 0.04 & $(0.00-0.31)$ & 0.003 & 0.40 & $(0.16-1.03)$ & 0.06 \\
\hline Triglycerides (mg/dL) & 1.00 & $(0.99-1.01)$ & 0.79 & 1.00 & $(0.99-1.01)$ & 0.61 \\
\hline Parathyroid hormone (pg/mL) & 1.11 & $(1.05-1.16)$ & $<0.001$ & 1.04 & $(1.01-1.07)$ & 0.009 \\
\hline Uric acid (mg/dL) & 0.96 & $(0.52-1.76)$ & 0.89 & 1.01 & $(0.68-1.49)$ & 0.98 \\
\hline Haptoglobin (mg/dL) & 1.02 & $(1.00-1.03)$ & 0.04 & 1.01 & $(1.00-1.02)$ & 0.15 \\
\hline Folate acid (ng/mL) & 0.80 & $(0.61-1.03)$ & 0.09 & 0.89 & $(0.76-1.05)$ & 0.16 \\
\hline Haemoglobin (g/dL) & 0.45 & $(0.20-1.02)$ & 0.06 & 0.55 & $(0.31-1.00)$ & 0.05 \\
\hline
\end{tabular}

*Vitamin D concentration was grouped to the following categories: Deficient (<20 ng/mL), Insufficient $(20-30 \mathrm{ng} / \mathrm{mL})$ and Sufficient $(>30 \mathrm{ng} / \mathrm{mL})$.

**Widowers and divorced are included under the "singles" family status category.

Moreover, findings of this study revealed that normal BMI was in correlation with sufficient vitamin D concentrations, indicating an inverse relationship between BMI and serum levels of vitamin D. Obesity poses a public health issue since the Byzantine Empire. (14). Overweight/obese people commonly have lower vitamin D levels due to decreased sunlight exposure and decreased physical activity, but mainly due to the increased uptake and sequestration of the fat-soluble vitamin D by adipose tissue. Obesity decreases the bioavailability of cutaneously synthesized vitamin $D$ by more than $50 \%(15,16)$.

Regarding lifestyle characteristics, alcohol intake was associated with sufficient levels of vitamin D compared to non-drinking subjects, while smoking was associated with sufficient levels of vitamin D. There are conflicting findings regarding alcohol consumption and serum vitamin D concentrations, which may partly be explained by alcoholic beverages as well as differences among groups of drinkers. Additionally, smokers were found to have lower BMI than non-smokers, which may be the link between smoking and vitamin D deficiency, as BMI and serum 25(OH) $\mathrm{D}$ levels are inversely related. However, other studies registering data on smoking and serum levels of $25(\mathrm{OH}) \mathrm{D}$ report either lower levels of $25(\mathrm{OH}) \mathrm{D}$ in smokers or no statistically significant difference between smokers and non-smokers regarding serum $25(\mathrm{OH}) \mathrm{D}$ levels $(17,18)$. However, the aforementioned studies used various forms of immunometric methods, whilst the ECLIA (Roche) method has been used in this study. Recently, Grimnes et al. performed a cross-sectional population-based study and one validation study comparing six different serum 25(OH)D assays.
This study indicated an impact of smoking on the measured serum levels of $25(\mathrm{OH})$ using the ECLIA (Roche) method compared to other methods in use. Still, the authors stated that, as their study did not give any molecular explanation for this observation, this issue needs to be further explored. Accordingly, the authors suggested to pay special attention to possible effects of smoking when current and new immunoassays are validated (19). Therefore, the finding of this study regarding the relationship between smoking and vitamin D levels can be attributed to the possible effect of smoking on the diagnostic method that has been used.

Regarding biomarkers, sufficient vitamin D concentrations correlated with low serum triglycerides, low serum calcium levels, low inflammation markers (CRP, haptoglobin), low kidney function markers (eGFR, increased serum cystatin C) and high haemoglobin. When additive linear regression models were used, correlations that remained statistically significant were those related to triglycerides, eGFR, haptoglobin, PTH and haemoglobin levels. A significant inverse association between serum vitamin D levels and triglycerides has recently been reported (20). Regarding eGFR, Choncol and Sqraqq demonstrated that patients with eGFR between $60-89 \mathrm{ml} / \mathrm{min} / 1.73 \mathrm{~m}^{2}$ had increased vitamin D levels, whereas patients with eGFR between $15-29 \mathrm{ml} / \mathrm{min} / 1.73 \mathrm{~m}^{2}$ had decreased vitamin D levels (21).

Another interesting finding was the association between sufficient vitamin D concentrations and haemoglobin levels. Kiss et al. have also demonstrated a significant and independent correlation between serum vitamin D and haemoglobin levels (22). There are several potential explanations for this finding. Vitamin 
D appears to directly stimulate erythroid precursor cells and it has been reported that hematons (the buffy coat of the bone marrow containing erythroid precursors, fibroblast, endothelial cells, lipid laden cells and macrophages) contain significantly higher concentrations of $25(\mathrm{OH}) \mathrm{D}$ and $1,25(\mathrm{OH}) 2 \mathrm{D}$ levels than bone marrow plasma. High local concentrations of $1,25(\mathrm{OH}) 2 \mathrm{D}$ in hematopoietic tissues may directly activate erythroid precursor cells in a paracrine fashion through the local activation of $25(\mathrm{OH}) \mathrm{D}$ in bone marrow though this is only a speculation. As it has been previously indicated, Vitamin D exerts its pleiotropic effects after binding to nuclear vitamin D receptor (VDR) that are present in over 30 human tissue/organs, amongst which the bone marrow (23). By binding, it modulates transcription of multiple vitamin D-dependent genes. As a result, vitamin D may directly modulate hematopoiesis-related proteins at the transcriptional level or it may be a necessary co-factor for the transcription of such proteins. Accordingly, vitamin D sufficiency might be a necessary factor for the biological effect of endogenous or exogenous erythropoietin. A greater prevalence and risk of anaemia in individuals with $25(\mathrm{OH}) \mathrm{D}$ deficiency compared with those with normal 25(OH)D levels has also been revealed previously (24). Another potential mechanism linking vitamin D to anaemia may be the association between vitamin $\mathrm{D}$ and parathyroid hormone. It has been shown that a low serum $25(\mathrm{OH}) \mathrm{D}$ vitamin level is associated with elevated serum intact PTH, while hyperparathyroidism, in turn, may lead to anaemia (25).

There is growing evidence suggesting that vitamin D and PTH may also play a role in the pathogenesis of cardiovascular disease. Hypovitaminosis D has been independently associated with increased rates of hypertension, diabetes peripheral arterial disease, myocardial infarction and related mortality (26-28). Vascular smooth muscle and endothelial cells possess the enzyme $25(\mathrm{OH}) \mathrm{D}-1 \alpha$-hydroxylase, which is responsible for the conversion of $25(\mathrm{OH}) \mathrm{D}$ to $1,25(\mathrm{OH}) 2 \mathrm{D}$. Vitamin D induces prostacyclin production in vascular smooth muscle cells, which prevents thrombus formation, cell adhesion, and smooth muscle cell proliferation. Furthermore, vitamin D regulates the expression of a number of other proteins relevant to the arterial wall including vascular endothelial growth factor, matrix metalloproteinase type 9, myosin, elastin, type I collagen, and $\gamma$-carboxyglutamic acid, a protein that protects against arterial calcification (29). Numerous studies have shown that patients with hyperparathyroidism experience an excess risk of mortality from cardiovascular disease. High PTH levels have also been independently associated with higher rates of cardiovascular disease in the general population. Vitamin D and PTH may influence cardiovascular risk through a shared association with atherosclerotic plaque formation and progression (30).

Patients with primary hyperparathyroidism have been reported to have increased arterial stiffness, altered vascular reactivity, left ventricular hypertrophy, and valvular calcification. Furthermore, receptors for PTH and PTH-related peptide have been located in the arterial endothelium as well as vascular smooth muscle cells (31). The inverse association between vitamin D concentrations and PTH levels that were found in this study remained statistically significant even after adjustment for potential confounders, such as age, sex, sunlight exposure, family status, physical activity, smoking habits, BMI, triglycerides, uric acid, haptoglobin, folate acid and haemoglobin.
This study demonstrated that participants with deficient vitamin D levels were more likely to have higher haptoglobin levels compared to subjects with sufficient vitamin D concentrations after adjustment for age, sex, sunlight exposure, family status, physical activity, smoking habits, BMI, triglycerides, uric acid and PTH. A plausible explanation for this finding is that subjects with vitamin $\mathrm{D}$ deficiency are in a state of mild inflammation compared to subjects with sufficient levels of vitamin D. In addition, haptoglobin is an acute phase protein that together with other acute phase reactants like CRP, serum amyloid A, ceruloplasmin, $\alpha 1$-antitrypsin, ferritin and fibrinogen have been occasionally linked to increased cardiovascular risk among different sub-populations studied $(32,33)$. Evidence is accumulating suggesting a relationship between vitamin D deficiency and chronic inflammatory/autoimmune disorders, such as rheumatoid arthritis, Crohn's disease and multiple sclerosis (12). It has been reported that vitamin D suppresses pro-inflammatory cytokines, including interleukin- 6 and tumor necrosis factor- $\alpha$, both in vitro and in vivo as well as circulating levels of MMP9 in chronic inflammatory disorders (34). Thus, the finding that, haptoglobin levels were lower between participants with vitamin D deficiency as compared to subjects with sufficient vitamin D concentrations could be explained by means of a mild inflammatory state among the first. Whether this inflammatory state is related to atherosclerosis or not remains to be elucidated.

Finally, the most interesting finding of our study was that one hour increase of sunlight exposure decreases by $70 \%$ the odds of having deficiency of vitamin D (i.e., $<20 \mathrm{ng} / \mathrm{mL}$ ), adjusted for age, sex, family status, physical activity, smoking habits, BMI, triglycerides, parathyroid hormone, uric acid, haptoglobin, folate acid, and haemoglobin, as compared to the sufficient levels (i.e., $>30 \mathrm{ng} / \mathrm{mL}$ ). By no means, do we recommend unprotected summer sun exposure due to overwhelming data that establish UV radiation as a carcinogen responsible for 1 million skin cancers per year in the United States alone as well as for photo-aging an essentially universal problem among whites in middle age and beyond $(35,36)$. These data also show that lifelong safe sun practices minimize both risks (35). If persons require 2-8 minutes of unprotected summer sun exposure to optimize cutaneous vitamin D synthesis, they could accomplish this in 10-20 minutes of exposure after applying an SPF 15-30 sunscreen in the customary manner (37). Therefore, sensible sun exposure in the spring, summer and fall, even for a short period of time but on a regular basis could have beneficial health effects.

There are few limitations regarding this study. First, sunlight exposure was recorded as the mean sunlight exposure estimated according to the $\mathrm{BBC}$ weather and a detailed history of sunlight exposure was not assessed at the time of the survey. Additionally, although the recruitment was planned to cover the whole year, data for February and March were limited. Therefore, it was not considered appropriate to estimate differences between summer and winter. Nevertheless, in the present study, season, outdoor working as well as leisure-time physical activity served as proxy measures of the effect of synthesis of vitamin D in the skin under UV exposure. Another concerning point is that the Elecsys assay VitD3 detects only VitD3 and possibly underestimates the concentration in people who take VitD2 medication, although this is not quite common on the Greek market. In addition, no data for participants' intake of vitamin D supplementation were available. 
Results of this study revealed that low levels of inflammation markers and high haemoglobin levels were related to sufficient concentrations of vitamin D, independently of age, sunlight exposure, and BMI. The so-called "sunshine vitamin" seems to have beneficial effects on a variety of biological parameters' levels, such as inflammation markers and haemoglobin. Simple lifestyle interventions like a slight increase of protected sunshine exposure could result in a substantial improvement on public health through multi-factorial, yet largely unknown mechanisms.

\section{Acknowledgements}

We are, particularly, grateful to the men and women from the residence of Athens, who participated in and collaborated on this research. We also wish to express our gratitude to: A. Giotopoulou and C. Katsagoni (field investigators from Harokopio University) for their substantial assistance in the enrolment of the participants. Galenica SA and the Hellenic Heart Foundation for partially funding the study (KA 00173).

\section{REFERENCES}

1. Thacher TD, Clarke BL. Vitamin D insufficiency. Mayo Clin Proc. 2011 Jan;86(1):50-60.

2. Holick MF. Calcium plus vitamin D and the risk of colorectal cancer. N Engl J Med. 2006 May 25;354(21):2287-8.

3. Munger KL, Levin LI, Hollis BW, Howard NS, Ascherio A. Serum 25-hydroxyvitamin D levels and risk of multiple sclerosis. JAMA. 2006 Dec 20;296(23):2832-8.

4. Rosen CJ. Clinical practice. Vitamin D insufficiency. N Engl J Med. 2011 Jan 20;364(3):248-54.

5. Holick MF, Binkley NC, Bischoff-Ferrari HA, Gordon CM, Hanley DA, Heaney RP, et al.; Endocrine Society. Evaluation, treatment, and prevention of vitamin D deficiency: an Endocrine Society clinical practice guideline. J Clin Endocrinol Metab. 2011 Jul;96(7):1911-30. Erratum in: J Clin Endocrinol Metab. 2011 Dec;96(12):3908.

6. Bischoff-Ferrari HA, Giovannucci E, Willett WC, Dietrich T, DawsonHughes B. Estimation of optimal serum concentrations of 25-hydroxyvitamin D for multiple health outcomes. Am J Clin Nutr. 2006 Jul;84(1):1828. Erratum in: Am J Clin Nutr. 2006 Nov;84(5):1253.

7. Lips P, Hosking D, Lippuner K, Norquist JM, Wehren L, Maalouf G, et al. The prevalence of vitamin $\mathrm{D}$ inadequacy amongst women with osteoporosis: an international epidemiological investigation. J Intern Med. 2006 Sep;260(3):245-54. Erratum in: J Intern Med. 2007 Apr;261(4):408.

8. Sullivan SS, Rosen CJ, Halteman WA, Chen TC, Holick MF. Adolescent girls in Maine are at risk for vitamin D insufficiency. J Am Diet Assoc. 2005 Jun;105(6):971-4.

9. World Medical Association Declaration of Helsinki: Ethical Principles for Medical Research Involving Human Subjects. 52nd WMA General Assembly. Edinburgh: WMA; 2000.

10. Bountziouka V, Bathrellou E, Giotopoulou A, Katsagoni C, Bonou M, Vallianou N, et al. Development, repeatability and validity regarding energy and macronutrient intake of a semi-quantitative food frequency questionnaire: methodological considerations. Nutr Metab Cardiovasc Dis. 2012 Aug;22(8):659-67.

11. Panagiotakos DB, Pitsavos C, Arvaniti F, Stefanadis C. Adherence to the Mediterranean food pattern predicts the prevalence of hypertension, hypercholesterolemia, diabetes and obesity, among healthy adults; the accuracy of the MedDietScore. Prev Med. 2007 Apr;44(4):335-40.

12. Holick MF. Vitamin D deficiency. N Engl J Med. 2007 Jul 19;357(3):26681.

13. Salamone LM, Dallal GE, Zantos D, Makrauer F, Dawson-Hughes B. Contributions of vitamin $\mathrm{D}$ intake and seasonal sunlight exposure to plasma 25-hydroxyvitamin D concentration in elderly women. Am J Clin Nutr. 1994 Jan;59(1):80-6.

14. Polychronopoulos E, Eftychiades A, Panagiotakos DB, Chrysohoou Ch, Toutouzas P, Marketos S. Obesity in byzantine and in modern era from a public health perspective. Cent Eur J Public Health. 2004 Dec;12(4):22830. Erratum in: Cent Eur J Public Health. 2005 Mar;13(1):10.
15. Konradsen S, Ag H, Lindberg F, Hexeberg S, Jorde R. Serum 1,25-dihydroxy vitamin $\mathrm{D}$ is inversely associated with body mass index. Eur J Nutr. 2008 Mar;47(2):87-91.

16. Wortsman J, Matsuoka LY, Chen TC, Lu Z, Holick MF. Decreased bioavailability of vitamin D in obesity. Am J Clin Nutr. 2000 Sep;72(3):6903. Erratum in: Am J Clin Nutr. 2003 May;77(5):1342.

17. Lorentzon M, Mellström D, Haug E, Ohlsson C. Smoking is associated with lower bone mineral density and reduced cortical thickness in young men. J Clin Endocrinol Metab. 2007 Feb;92(2):497-503.

18. Brot C, Jorgensen NR, Sorensen OH. The influence of smoking on vitamin D status and calcium metabolism. Eur J Clin Nutr. 1999 Dec;53(12):920-6.

19. Grimnes G, Almaas B, Eggen AE, Emaus N, Figenschau Y, Hopstock LA, et al. Effect of smoking on the serum levels of 25-hydroxyvitamin D depends on the assay employed. Eur J Endocrinol. 2010 Aug; 163(2):33948. Erratum in: Eur J Endocrinol. 2010 Dec;163(6):965.

20. Karhapää P, Pihlajamäki J, Pörsti I, Kastarinen M, Mustonen J, Niemelä O, et al. Diverse associations of 25-hydroxyvitamin D and 1,25-dihydroxyvitamin D with dyslipidaemias. J Intern Med. 2010 Dec;268(6):604-10.

21. Chonchol M, Scragg R. 25-Hydroxyvitamin D, insulin resistance, and kidney function in the Third National Health and Nutrition Examination Survey. Kidney Int. 2007 Jan;71(2):134-9.

22. Kiss Z, Ambrus C, Almasi C, Berta K, Deak G, Horonyi P, et al. Serum $25(\mathrm{OH})$-cholecalciferol concentration is associated with hemoglobin level and erythropoietin resistance in patients on maintenance hemodialysis. Nephron Clin Pract. 2011;117(4):c373-8.

23. Norman AW. Minireview: vitamin D receptor: new assignments for an already busy receptor. Endocrinology. 2006 Dec;147(12):5542-8.

24. Sim JJ, Lac PT, Liu IL, Meguerditchian SO, Kumar VA, Kujubu DA, et al. Vitamin D deficiency and anemia: a cross-sectional study. Ann Hematol. 2010 May;89(5):447-52.

25. Gómez-Alonso C, Naves-Díaz ML, Fernández-Martín JL, Díaz-López JB, Fernández-Coto MT, Cannata-Andía JB. Vitamin D status and secondary hyperparathyroidism: the importance of 25-hydroxyvitamin D cut-off levels. Kidney Int Suppl. 2003 Jun;(85):S44-8.

26. Forman JP, Giovannucci E, Holmes MD, Bischoff-Ferrari HA, Tworoger SS, Willett WC, et al. Plasma 25-hydroxyvitamin D levels and risk of incident hypertension. Hypertension. 2007 May;49(5):1063-9.

27. Melamed ML, Michos ED, Post W, Astor B. 25-hydroxyvitamin D levels and the risk of mortality in the general population. Arch Intern Med. 2008 Aug 11;168(15):1629-37.

28. Wang TJ, Pencina MJ, Booth SL, Jacques PF, Ingelsson E, Lanier K, et al. Vitamin D deficiency and risk of cardiovascular disease. Circulation. 2008 Jan 29;117(4):503-11.

29. Hyppönen E, Boucher BJ, Berry DJ, Power C. 25-hydroxyvitamin D, IGF-1, and metabolic syndrome at 45 years of age: a cross-sectional study in the 1958 British Birth Cohort. Diabetes. 2008 Feb;57(2):298-305.

30. Tai K, Need AG, Horowitz M, Chapman IM. Glucose tolerance and vitamin D: effects of treating vitamin D deficiency. Nutrition. 2008 Oct;24(10):950-6.

31. Andersson P, Rydberg E, Willenheimer R. Primary hyperparathyroidism and heart disease - a review. Eur Heart J. 2004 Oct;25(20):1776-87.

32. Engström G, Hedblad B, Stavenow L, Jonsson S, Lind P, Janzon L, et al. Incidence of obesity-associated cardiovascular disease is related to inflammation-sensitive plasma proteins: a population-based cohort study. Arterioscler Thromb Vasc Biol. 2004 Aug;24(8):1498-502.

33. Vallianou NG, Evangelopoulos AA, Panagiotakos DB, Georgiou AT, Zacharias GA, Vogiatzakis ED, et al. Associations of acute-phase reactants with metabolic syndrome in middle-aged overweight or obese people. Med Sci Monit. 2010 Feb;16(2):CR56-60.

34. Timms PM, Mannan N, Hitman GA, Noonan K, Mills PG, SyndercombeCourt D, et al. Circulating MMP9, vitamin D and variation in the TIMP-1 response with VDR genotype: mechanisms for inflammatory damage in chronic disorders? QJM. 2002 Dec;95(12):787-96.

35. Gilchrest BA. Sun exposure and vitamin D sufficiency. Am J Clin Nutr. 2008 Aug;88(2):570S-577S

36. Plesko I, Vlasák V, Kramárová E, Obsitníková A. The role of the registry in the study of relation between cancer and environment experiences from Slovakia. Cent Eur J Public Health. 1993 Jun;1(1):19-24.

37. Holick MF, Jenkins M. The UV advantage. New York: iBooks; 2004.

Received December 3, 2011 Accepted in revised form October 12, 2012 